\title{
Karakterisasi Kandungan Fitokimia Estrak Daun Karamunting (Melastoma malabatchricum L.) Menggunakan Metode Gas Chromatography Mass Spectrometry (GC-MS)
}

\section{Characterisation of Phytochemical Content of Leaf Extract from Karamunting (Melastoma malabatchricum L.) Using Gas Chromatography Mass Spectrometry (GC-MS).}

\author{
Kartina $^{1 *}$, Mohammad Wahyu Agang ${ }^{1}$, Muhammad Adiwena ${ }^{1}$ \\ ${ }^{1}$ Fakultas Pertanian, Universitas Borneo Tarakan, Jl. Amal Lama No. 1, Kalimantan Utara, Indonesia \\ E-mail:kartina@borneo.ac.id *Penulis korespondensi
}

\begin{abstract}
Melastoma malabatchricum $\mathrm{L}$. is a type of plant that is widely grown in South and Southeast Asia, including Indonesia and it has benefits as a medicinal plant. In Kalimantan, Karamunting leaves is used to treat wounds, fever, diarrhea, and tannins in its root is used to darken teeth or eyebrows. The usage standard of this plant as an herbal medicine is still based on people's habits, so research needs to be done to find out how much phytochemical content is found in $M$. malabatchricum $L$. The priorknowledge of phytochemical $M$. malabatchricum $\mathrm{L}$. becomes the basis for developing its potential as a plant medicine and its use in various fields. This research was conducted at the Agriculture Faculty Agrotechnology Laboratory, UBT. The research consisted of characterization of Karamunting plants, leaf extraction by maceration, and phytochemical content analysis with GCMS. The results showed that $M$. malabatchricum leaf extract contained phenol compounds of $36.32 \%$, fatty acids $(20.74 \%)$, terpenoids $(9.13 \%)$, sterols $(5.77 \%)$, alkaloids (4.8\%), amino acids (3.5\%), aldehyde (3.15\%), alcohol (1.54\%) and several other compounds. Some types of compounds found are known to have potential as antibacterial, antiviral, antioxidant, cytotoxic, anticoagulant, wound healing, antidiareous, antivenom and anti-inflammatory.
\end{abstract}

Key word: Melastoma malabathricum L., Phytochemical, gas chromatography mass spectrometry (GC-MS)

\begin{abstract}
Abstrak
Melastoma malabatchricum L. merupakan jenis tumbuhan yang banyak tumbuh di Asia Selatan dan Asia Tenggara, termasuk Indonesia dan bermanfaat sebagai tanaman obat. Di Pulau Kalimantan, Indonesia, masyarakat menggunakan daunnya untuk mengobati luka, demam, diare, dan tanin pada akarnya digunakan untuk menghitamkan gigi atau alis. Standar penggunaan tanaman ini sebagai obat herbal masih didasarkan pada kebiasaan masyarakat, sehingga perlu dilakukan penelitian untuk mengetahui seberapa besar kandungan fitokimia yang terdapat pada tumbuhan Melastoma malabatchricum L. Pengetahuan awal tentang kandungan fitokimia tumbuhan Melastoma malabatchricum $\mathbf{L}$. menjadi dasar untuk melakukan pengembangan khususnya potensinya sebagai tanaman obat, maupun pemanfaatannya di berbagai bidang. Pelaksanaan penelitian meliputi: karakterisasi tumbuhan Melastoma malabatchricum L., ekstraksi daun dengan maserasi, dan analisis kandungan fitokimia dengan $G C$-MS. Hasil penelitian menunjukkan bahwa ekstrak daun Melastoma malabatchricum $\mathrm{L}$ mengandung fitokimia dintaranya senyawa fenol sebesar $36,32 \%$, asam lemak $(20,74 \%)$, terpenoid $(9,13 \%)$, sterol $(5,77 \%)$, alkaloid $(4,8 \%)$, asam amino $(3.5 \%)$, aldehid $(3,15 \%)$, alkohol $(1,54 \%)$, dan beberapa senyawa lainnya.
\end{abstract}

Kata kunci: Melastoma malabathricum L., Fitokimia, gas chromatography mass spectrometry $(G C-M S)$ 


\section{Pendahuluan}

Tanaman obat tradisional telah lama menjadi sasaran pencarian obat baru seiring dengan peningkatan kebutuhan masyarakat akan obat herbal. Keberadaan tumbuhtumbuhan yang mempunyai potensi sebagai obat menjadi fokus penelitian dalam rangka membantu meningkatkan derajat kesehatan masyarakat dewasa ini.

Karamunting

(Melastoma

malabatchricum L.) merupakan tumbuhan yang tergolong semak dan banyak ditemukan di seluruh negara-negara Asia Tenggara, termasuk Indonesia (van Valkenberg dan Bunyapraphatsara, 2001). Tanaman ini tumbuh liar dan berlimpah di daerah tropis, terutama di daerah lembab, dan dapat ditemukan di Kepulauan Samudera Hindia, di seluruh Asia Selatan dan Tenggara, Cina, Taiwan, Australia, dan Samudra Pasifik Selatan (Wong, 2008). Secara umum, bagian daun, akar dan buah tanaman Karamunting digunakan sebagai obat tradisional di Malaysia, India, dan Indonesia untuk mengobati berbagai jenis penyakit seperti diare, disentri, keputihan, wasir, sakit gigi, sakit perut, perut kembung, sakit kaki dan sariawan (Koay, 2008; Begum dan Nath, 2000; Bharadwaj dan Gakhar, 2005). Selain itu Hugh Tan dan Yeo (2009) melaporkan, dalam pengobatan tradisional Tiongkok, biji Karamunting dapat menyembuhkan diare. Di Malaysia, rebusan daun dapat diminum untuk mengobati sakit perut, sedangkan di Indonesia digunakan untuk menyembuhkan luka dengan cara daun ditumbuk dan ditempelkan pada luka (Heyne, 1987; Latif, 1992). Masyarakat di kota Tarakan, Provinsi Kalimantan Utara, juga telah lama memanfaatkan tanaman ini sebagai obat tradisional.

Pada umumnya pengetahuan terkait penggunaan tumbuhan obat diperoleh secara turun-menurun dari tetua desa secara lisan. Masyarakat lokal jarang sekali ada yang menyebarkan pengetahuan tersebut dalam tulisan. Selain itu, maraknya gaya hidup modern, sedikit demi sedikit mengubah pola pikir masyarakat menjadi lebih menyukai produk obat buatan pabrik dibanding mengkonsumsi obat-obatan tradisional (Rahyuni dkk., 2013). Generasi muda yang merupakan penerus ilmu obat tradisional, mulai meninggalkan tumbuhan obat lalu beralih pada penggunaan obat kimia (Suryadarma, 2010). Hal ini menyebabkan banyak informasi tumbuhan obat yang tidak terdokumentasikan dan khasiatnya tidak dapat dipelajari lebih lanjut. Oleh karena itu, penelitian tentang tumbuhan obat perlu dikembangkan dan dikaji lebih lanjut.

Kandungan fitokimia daun Karamunting dari beberapa literatur hanya menyebutkan data secara kualitatif. Informasi seberapa besar kandungan fitokimia khususnya metabolit sekunder pada daun Karamunting belum diketahui secara rinci. Selain itu, Karamunting yang tumbuh di tempat yang berbeda diduga mengandung komposisi fitokimia yang berbeda pula. Hal ini disebabkan karena sintesis senyawa aktif suatu tanaman dinyatakan sebagai hasil dari rangsangan eksternal. Suatu organisme mampu menghasilkan kelompok metabolit yang sama sekali berbeda. Hal tersebut dipengaruhi oleh berbagai kondisi lingkungan, durasi dan intensitas stres, komposisi, dan plastisitas genetik suatu tanaman (Zhao et al., 2005).

Data terkait fitokimia khususnya pada daun tumbuhan tersebut belum diteliti. Padahal penggunaannya sebagai obat tradisional telah diketahui sejak lama. Oleh karena itu, penelitian ini bertujuan untuk mengetahui kandungan fitokimia khususnya metabolit sekunder ekstrak daun Karamunting yang diperoleh dari Gunung Slipi Kota Tarakan dengan menggunakan metode Gas Chromatography Mass Spectrometry (GCMS).

Uji fitokimia ini merupakan langkah awal sebagai upaya untuk mengetahui kandungan senyawa aktif yang terdapat pada tumbuhan obat lokal agar dapat dimanfaatkan secara tepat dan lebih luas. Selain mengetahui kandungan fitokimia daun Karamunting, peranan senyawa tersebut dalam sistem biologis akan dipaparkan berdasarkan tinjauan beberapa literatur sehingga pemanfaatan 
tumbuhan Karamunting sebagai obat dapat digunakan secara lebih optimal oleh masyarakat.

\section{Metode Penelitian}

Penelitian ini dilaksanakan di Laboratorium Fakultas Pertanian Universitas Borneo Tarakan, pada bulan Februari 2018 Mei 2018. Bahan yang digunakan dalam penelitian ini, yaitu: daun Karamunting (berasal dari Gunung Slipi, Kota Tarakan, Provinsi Kalimantan Utara, Indonesia), aquades, tisu, kertas saring, dan etanol $96 \%$ sebagai pelarut ekstrak. Alat yang digunakan dalam penelitian ini, yaitu: toples kaca, kertas label, gunting, rotary evaporation, timbangan analitik, alat tulis, dan blender untuk menghaluskan daun. Penelian ini terdiri dari karakterisasi, penyiapan simplisia, ekstraksi dan pengujian kandungan fitokimia ekstrak dengan metode GCMS.

Langkah awal dalam penelitian ini yaitu Pembuatan simplisia. Pembuatan simplisia terdiri dari: pengumpulan daun keramunting, sortasi basah, pencucian, perajangan, pengeringan, sortasi kering, pengepakan dan penyimpanan (Departemen Kesehatan Republik Indonesia, 1985). Simplisia yang sudah dibuat diekstraksi dan dianalisis kandungan fitokimianya menggunkan metode GC-MS.

\section{a. Karakterisasi}

Karakterisasi Karamunting dilakukan di Laboratorium Fisiologi Tumbuhan, Fakultas Pertanian Universitas Borneo Tarakan.

\section{b. Penyiapan Simplisia}

Pembuatan simplisia terdiri dari: pengumpulan simplisia, sortasi basah, pencucian, perajangan, pengeringan, sortasi kering, pengepakan dan penyimpanan (Departemen Kesehatan Republik Indonesia, 2008).

1. Tumbuhan dikumpulkan secara manual di lapangan. Daun yang dipilih adalah daun yang muda maupun daun yang tua dari beberapa tanaman (komposit).

2. Sortasi basah dimaksudkan untuk memisahkan kotoran atau bahan-bahan asing lainnya dari tumbuhan sebelum pencucian, yaitu dengan membuang bagian-bagian yang tidak perlu sebelum pengeringan, sehingga didapatkan daun yang layak untuk digunakan

3. Pencucian dimaksudkan untuk menghilangkan tanah dan pengotor lainnya yang melekat pada tumbuhan. Pencucian dilakukan dengan air bersih yaitu menggunakan air yang mengalir.

4. Perajangan dilakukan untuk mempermudah proses pengeringan, pengepakan dan penggilingan.

5. Pengeringan daun menggunakan oven $\left(30-40^{\circ} \mathrm{C}\right)$. Pengeringan ini berlangsung hingga diperoleh kadar air $\pm 10 \%$ (Manoi, 2006).

\section{c. Ektraksi (Maserasi)}

Sebanyak 1000 gr simplisia kering di blender. Sampel yang telah diblender diekstraksi dengan menggunakan etanol $96 \%$ sebanyak $3000 \mathrm{ml}$ (1:3). Kemudian didiamkan selama 2 hari dan diaduk setiap harinya selama 5 menit. Ekstrak kemudian disaring dan diuapkan menggunakan rotary evaporation sehingga diperoleh ekstrak berbentuk pasta.

\section{d. Analisis Fitokimia Ekstrak (GCMS)}

Kandungan fitokimia ekstrak daun Karamunting dianalisis dengan GC-MS di Pusat Laboratoirum Forensik Kepolisian Republik Indonesia (PUSLABFOR POLRI) di Jakarta.

\section{Hasil dan Pembahasan}

Tumbuhan tergolong perdu tinggi $\pm 1-4$ m. Batang bercabang, bersisik dan berambut. Daun tunggal, bertangkai, dan letak daun berhadapan bersilang. Helai daun memanjang (lonjong), ujung lancip, pangkal membulat dengan tepi rata, permukaan berambut pendek, panjang 6-13 cm, lebar $0,7-8 \mathrm{~cm}$, warnanya 
hijau. Bunga majemuk keluar diujung dengan jumlah bunga tiap malai 4-10, warnanya ungu kemerahan. Saat buah masak akan

Kingdom : Plantae

Devisi : Spermatophyta

Class : Dicotylendonae

Ordo : Myrtales

Family : Melastomataceae

Genus : : Melastoma

Species : Melastoma malabathricum $\mathrm{L}$

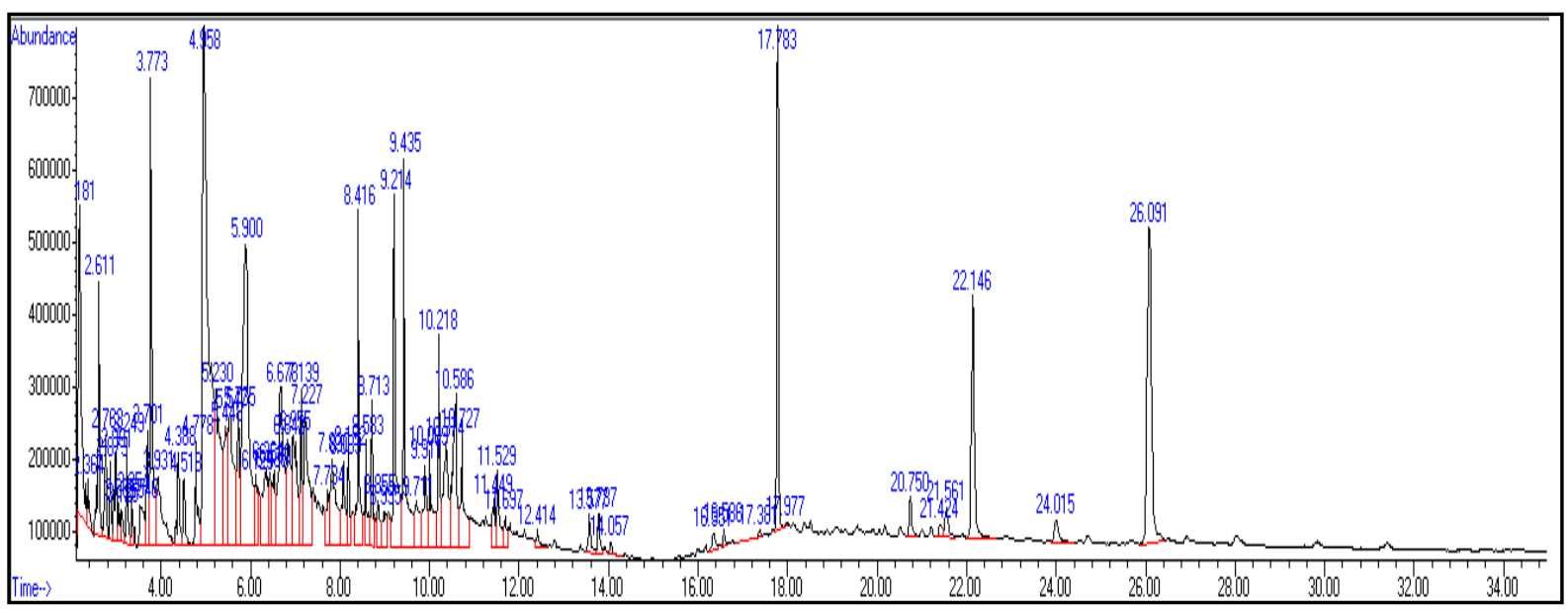

Gambar 1. Kromatogram GC-MS ekstrak etanol daun Karamunting (Melastoma malabathricum L.)

Analisis dengan metode GC-MS merupakan kunci dalam analisis komponen kimia tanaman yang belum diketahui (Revanthi, et al. 2015). Analisis dengan GCMS telah banyak digunakan dalam mengidentifikasi ratusan komponen senyawa yang terdapat pada sel tanaman yang tidak dapat dilakukan dengan skrining fitokimia biasa. Hal ini disebabkan skrining fitokimia terbatas pada identifikasi golongan senyawa (Hamuel, 2012).

Dari hasil analisis GCMS berdasarkan kromatogram (Gambar 1.) terdapat satu puncak yang paling dominan diihat dari persentase area yaitu $14,77 \%$. Senyawa tersebut adalah 1,2,3-benzenetriol yang merupakan golongan senyawa fenol. Puncak serapan dominan tersebut diperoleh dengan waktu retensi 4,954 dan 5,222 menit. Senyawa mayor lain yang teridentifikasi adalah d'allose pada waktu retensi 5,892 dengan persentase area 7,55\%. Hexadecanoic acid atau disebut asam palmitat merupakan golongan senyawa asam lemak teridentifikasi sebesar 5,97\% pada waktu retensi 9,212 dan 9,429 menit (Tabel 1). Struktur kimia senyawa mayor tersebut dapat dilihat pada tabel 2 .

Tabel 1. Hasil analisis GC-MS komponen kimia ekstrak etanol daun Karamunting (M. malabathricum L.)

\begin{tabular}{cccl}
\hline \hline No & $\begin{array}{c}\text { Waktu Retensi } \\
\text { (menit) }\end{array}$ & $\begin{array}{c}\% \\
\text { Area }\end{array}$ & \multicolumn{1}{c}{ Komponen Kimia } \\
\hline \hline 1 & 2,607 & 1,67 & $\begin{array}{l}\text { 3-fluoro-2,5-dimethyl-2,4-hexadien e - 2,4-Hexadiene, 3-fluoro-2,5- } \\
\text { dimethyl-(CAS) }\end{array}$ \\
\hline 2 & 2,188 & 3,40 & Glycerin \\
\hline 3 & 3,931 & 3,15 & 2-Furancarboxaldehyde, 5-(hydroxym ethyl)- \\
\hline & 3,931 & 1,69 & Imidazole-4-carboxylic acid, 1-methyl- \\
\hline 6 & 4,954 & 11,55 & 1,2,3-Benzenetriol \\
\hline 7 & 5,220 & 3,222 & 1,2,3-Benzenetriol \\
\hline
\end{tabular}




\begin{tabular}{|c|c|c|c|}
\hline No & $\begin{array}{c}\text { Waktu Retensi } \\
\text { (menit) }\end{array}$ & $\begin{array}{c}\% \\
\text { Area }\end{array}$ & Komponen Kimia \\
\hline 8 & 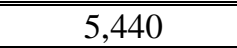 & 1,75 & 1,2,3-Benzenetriol-Pyrogallol - C.I. \\
\hline 9 & 5,540 & 2,68 & 1,2,3-Benzenetriol-Pyrogallol-C.I. \\
\hline 10 & 5,742 & 1,23 & 6,8-dimethylbenzocyclooctene-Benzocyclooctene, 6,8-dimethyl-(CAS \\
\hline 11 & 5,892 & 7,55 & d-Allose \\
\hline 12 & 6,362 & 1,53 & Phenol, 2-(butylthio)- Phenol, o-(butylthio)- \\
\hline 13 & 6,680 & 3,22 & 1,6-Anhydro-.beta.-D-glucofuranose Silane \\
\hline 14 & 6,848 & 1,55 & 6,8-dimethylbenzocyclooctene -Be \\
\hline 15 & 6,949 & 2,07 & Tetramethyl-1,3,4,2,5-thiadiazadip hospholidine \\
\hline 16 & 7,133 & 1,21 & Phenol, 4-(ethoxymethyl)-2-methoxy \\
\hline 17 & 7,233 & 2,23 & 6,8-dimethylbenzocyclooctene - Benzocyclooctene, \\
\hline 18 & 7,837 & 1,86 & Phenol, 4-(ethoxymethyl)-2-methoxy \\
\hline 19 & 8,424 & 1,87 & Benzene, 1,2,3-trimethoxy-5-methyl \\
\hline 20 & 9,212 & 2,97 & n-Hexadecanoic acid \\
\hline 21 & 9,429 & 3,00 & Hexadecanoic acid, ethyl ester (CAS) \\
\hline 22 & 10,016 & 1,17 & Benzene, 1-methyl-2-(phenylmethyl) - Methane, phenyl-o-tolyl-. \\
\hline 23 & 10,586 & 2,31 & 9,12,15-Octadecatrienoic acid, \\
\hline 24 & 10,217 & 1,47 & Phytol \\
\hline 25 & 10,368 & 1,90 & Z) 6,(Z) 9-Pentadecadien-1-ol \\
\hline 26 & 10,720 & 1,45 & Octadecanoic acid, ethyl ester (CAS) \\
\hline 27 & 17,778 & 3,79 & Squalene \\
\hline 28 & 22,153 & 2,99 & Vitamin e-dl-.alpha.-Tocopherol \\
\hline 29 & 26,092 & 5,27 & $\begin{array}{l}\text { (23S)-ethylcholest-5-en-3.beta.-ol -Cholest-5-en-3-ol, 23-ethyl- } \\
\text {,(3.beta.,23S)- (CAS) }\end{array}$ \\
\hline
\end{tabular}

Senyawa fenol yang paling banyak ditemukan adalah 1,2,3-Benzenetriol dan Vitamin e dl-.alpha.-Tocopherol. Golongan senyawa asam lemak didominasi oleh hexadecanoic acid atau asam palmitat, linoleat acid atau asam karboksilat adalah asam lemak omega-6 dan octadecatrienoic acid. Jenis terpenoid yang paling banyak ditemukan adalah squalene, phytol dan octadecene, sedangkan golongan sterol yang banyak teridentifikasi adalah ethylcholest dan stigmasterol.

Tabel 2. Struktur beberapa senyawa mayor yang memiliki aktivitas biologis yang teridentifikasi pada ekstrak daun Karamunting (Melastoma malabathricum L.)

\begin{tabular}{clcc}
\hline No & & Nama dan Struktur Senyawa & Golongan Senyawa \\
\hline 1 & 1,2,3-Benzenetriol & Monosakarida \\
\hline 2 & D-Allose & Asam Lemak \\
\hline 4 & $\begin{array}{l}\text { Hexadecanoic acid, ethyl ester }(\text { CAS }) \\
\text { ethyl, }(3 . \text { beta. } 23 S) \text { - }(\text { CAS })\end{array}$ & Sterol \\
& &
\end{tabular}


Pada Tabel 1 diketahui bahwa ekstak daun Karamunting didominasi oleh golongan senyawa Fenol. Senyawa fenol merupakan senyawa penting dalam fisiologi tumbuhan karena berperan dalam pigmentasi, rasa, untuk pertumbuhan, reproduksi dan untuk ketahanan tanaman terhadap patogen dan predator (Blomhoff, 2010). Senyawa 1,2,3 Benzenetriol yang merupakan senyawa dominan yang dtemukan pada ekstrak memiliki peran penting bagi fisiologis tubuh organisme. Ghopalakhrishnan (2011) melaporkan bahwa senyawa yang dapat berperan sebagai antioksidan yaitu 4H-Pyran-4-one, 2,3dihydro-3,5-di dan 1,2,3 Benzenetriol. Hal ini menunjukkan bahwa daun Karamunting memiliki potensi yang cukup kuat sebagai sumber antioksidan.

Selain Benzenetriol senyawa fenol lain yang teridentifikasi adalah senyawa Vitamin $e$ dl-alpha.-Tocopherol yaitu dengan persentase area sebesar 5,27\%. Menurut Sell (2003), vitamin $\mathrm{E}$ atau tocopherol merupakan antioksidan penting yang dapat mencegah kerusakan oksidatif pada sel. Telah diketahui bahwa kebanyakan antioksidan alami bekerja secara sinergis untuk menghasilkan aktivitas antioksidan berspektrum luas yang menciptakan sistem pertahanan yang efektif melawan serangan dari radikal bebas (Pino, et al., 2010). D' allose merupakan salah satu jenis monosakarida yang termasuk rare sugar. D'allose terbukti bermanfaat dalam melindungi cedera ginjal akut dalam respons inflamasi sistemik terhadap lipopoliskarida (Ueki et al, 2008).

Ekstrak daun Karamunting juga mengandung senyawa golongan asam lemak. Menurut de Roos. et al., 2001; Lichtenstein et al., 2006 setiap jenis asam lemak memiliki dampak fisiologis dan biologis yang berbeda bagi kesehatan. Asam lemak adalah prekusor sekelompok senyawa elkosanad yang mirip hormon yaitu prostaglandin, prostasiklin, tromboksan dan leukotrion. Senyawa ini berperan mengatur tekanan darah, denyut jantung, fungsi kekebalan, rangsangan sistem saraf, kontraksi otot dan untuk penyembuhan luka (Maycs, 2003). Hexadecanoid acid atau lebih dikenal asam palmitat merupakan kelompok asam lemak yang ditemukan dominan dalam ekstrak. Pada dasarnya tubuh memerlukan asam lemak bebas seperti palmitat, namun dalam jumlah sedikit. Fungsinya antara lain sebagai pelarut vitamin A dan E. Hexadecanoic acid, Octadecanoic acid pada beberapa riset diketahui memiliki peran dalam sistem biologis yaitu sebagai antibakteri dan antifungi (Mustapha, 2016). Rajeswari et al. (2015) menambahkan bahwa Octadecanoic acid dapat berperan sebagai antioksidan dan antiinflamasi.

Senyawa mayor lain yang terdapat pada daun Karamunting adalah ethylcholest yang merupakan golongan senyawa sterol. Sterol (steroid) pada tanaman juga dikenal sebagai fitosterol (Brielmann et al., 2006). Penelitian Kris-Etherton et al., 2002, membuktikan bahwa fitosterol efektif menurunkan resiko penyakit kardiovaskular. Kolesterol merupakan molekul penting dalam tubuh yakni sebagai prekusor beberapa hormone seperti testosterone dan estrogen, menjaa cairan sel membrane dan berkontribusi dalam pembentukan asam empedu yang membantu mencerna lemak.

Senyawa sterol lain yang teridentifikasi pada ekstrak adalah stigamsterol. Stigmasterol merupakan golongan fitosterol sebagai bagian dari sterol. Jadi dapat dikatakan bahwa stigmasterol merupakan senyawa turunan dari fitosterol. Asupan makanan yang mengandung stigmasterol dapat mencegah perkembangan sel kanker di dalam tubuh. Alasannya, stigmasterol memiliki struktur yang hampir sama dengan kolesterol namun memiliki sifat yang berlawanan. Di dalam tubuh kita, asupan kolesterol yang berlebihan bisa menyebabkan berbagai macam penyakit. Bahkan penumpukan kolesterol yang berlebih di dalam tubuh bisa menyebabkan obesitas. Kolesterol berlebih bisa dianggap sebagai racun oleh 
tubuh. Lama kelamaan, racun tersebut menjadi berbahaya dan dapat berkembang menjadi sel kanker. Gabay (2009), melaporkan bahwa Stigmasterol mampu menghambat degradasi matriks mediator yang biasanya terlibat dalam degradasi kartilago yang menginduksi osteoarthritis (OA) melalui penghambatan jalur Nf-Kb. Sterol memiliki bioaktivitas yang penting, misalnya dalam pembentukan struktur membran, pembentukan hormon dan vitamin $D$, sebagai penolak dan penarik serangga dan sebagai antimikroba (Novitasari et al, 2016).

Setiap jenis tumbuhan yang berpotensi sebagai obat memiliki komposisi fitokimia yang berbeda. Data tersebut sangat diperlukan sebagai informasi awal sehingga pemanfaatan suatu tanaman sebagai tanaman obat dapat diketahui. Dalam perkembangannya, dapat dijadikan dasar dalam mengisolasi senyawa yang terdapat pada tumbuhan tersebut.

Karamunting mengandung berbagai jenis senyawa aktif yang dapat dijadikan sebagai bahan dasar untuk antibakteri, antijamur maupun untuk penyembuhan luka. Pada dasarnya sel tanaman mengandung dua tipe metabolit, yaitu metabolit primer seperti karbohidrat, asam amino, lemak, vitamin dan metabolit sekunder seperti golongan senyawa alkaloid, flavonoid, terpenoid, steroid dan tannin. Metabolit sekunder merupakan sumber bagi bahan farmasetika, bahan tambahan makanan, digunakan sebagai bahan parfum maupun pestisida. Oleh karena itu, informasi kandungan senyawa aktif pada suatu tanaman dan peranannya dalam kehidupan perlu diketahui agar dapat dimanfaatkan secara luas bagi masyarakat.

\section{Simpulan}

Kandungan fitokimia pada eksrak daun Karamunting asal Gunung Slipi Kota Tarakan didominasi oleh senyawa golongan fenol yaitu 1,2,3-Benzenetriol, monosakarida yaitu D'allose, senyawa golongan asam lemak yaitu Hexadecanoic acid, dan sterol yaitu ethylcholest. Senyawa tersebut berperan sebagai antioksidan, anti inflamasi, antifungi dan antibakteri dan fitosterol efektif menurunkan resiko penyakit kardiovaskular.

\section{Ucapan Terima Kasih}

Tim peneliti mengucapkan terima kasih kepada Kementerian Riset, Teknologi dan Pendidikan Tinggi atas bantuan dana riset dalam skema Penelitian Dosen Pemula (PDP) tahun 2018.

\section{Daftar Pustaka}

Begum, D. and. Nath, S.C. 2000. "Ethnobotanical reviewof medicinal plants used for skin diseases and related problems in Northeastern India," Journal of Herbs., Spices and Medicinal Plants, 7: 55-93.

Bharadwaj, S. and Gakhar, S.K. 2005. "Ethnomedicinal plants used by tribals of Mizorum to use cuts and wounds,' Indian Journal of Traditional Knowledge, 4:75-80.

Blomhoff, R. 2010. Role of Dietary Phytochemicals in Oxidative Stress. Oslo: The Norwegian Academy of Science and Letters. Proceedings from a Symposium.

Brielmann, H.L., Setzer, W.N., Kaufman, P.B., Kirakosyan, A. and Cseke, L.J. 2006. Phytochemicals: the chemical components of plants, p.1-49. In L.J. Cseke, A. Kirakosyan, P.B. Kaufman, S.L. Warber, J.A. Duke and H.L. Brielmann (Eds.). Natural Products From Plants. CRC Press: New York.

Dalimartha, S. 2000.Atlas Tumbuhan Obat Indonesia. Bogor :TrobusAgriwidya.

Departemen Kesehatan Republik Indonesia. 2008. Farmakope Herbal Indonesia (Edisi I). Jakarta: Departemen Kesehatan Republik Indonesia.

De Roos N.M., Bots M.L., dan Katan M.B. 2001. Replacement of dietary saturated fatty-acid and stearic acid by trans fatty acids lower serum HDL cholesterol and impairs endothelial function in healthy men and women. Arterioscler Thromb Vasc Biol, 21 (7): 1233-7.

Gabay, O., Sanchez, C., Salvat, C., Chevy, F., Breton, M., Nourissat, G., Wolf, C., Jacquest, C., and Berenbaum, F. 2009. Stigmasterol: a phytosterol with potential anti-osteoarthritic properties. Osteoarthritis and Cartilage, 18:106-116. 
Gopalakrishnan, S. 2011. GC-MS analysis of some bioactive constituents of Mussaenda frondosa Linn. Intl. J. Pharma. and Bio. Sci, 2(1):313320.

Hamuel, D.J. 2012. Phytochemicals: Extraction methods, basic structures and mode of action as potential chemotherapeutic agents. Departement of Microbiology School of Pure and Applied Sciences, Federal University of Technology Yola, Nigeria.

Heyne, K. 1987. Tumbuhan Berguna Indonesia. Jilid I dan II. Terj. Badan Libang Kehutanan. Cetakan I: Koperasi karyawan Departemen Kehutanan, Jakarta Pusat.

Hugh Tan, T.W. and Yeo, C.K. 2009. "The Potential of Native Woody Plants for Enhancing the Urban Waterways and Waterbodies Environment in Singapore," Raffles Museum of Biodiversity Research and Singapore-Delft Water Alliance, National University Singapore, Singapore. p. 14.

Koay, S.S. 2008. "Establishment of cell suspension culture of Melastoma malabathricum L. for the production of anthocyanin," PhD. Thesis, Universiti Sains Malaysia, Pulau Pinang, Malaysia.

Kris-Etherton, P.M., Hecker, K.D., Bonanome, A., Coval S.M., Binkoski, A.E., Hilpert, K.F., Griel, A.E. and Etherton, T.D. 2002. Bioactive compounds in foods: their role in the prevention of cardiovascular disease and cancer. Am. J. Med, 113 (9):71-88

Lichtenstein AH, Appel LJ, Brands M, Carnethon M, Daniels S, Franch HA. 2006. Diet and lifestyle recommendation revision: A scientific statement from The American Heart Association Nutrition Committee. Circulation, 114 (1):82-96.

Manoi, F. 2006. Pengaruh Cara Pengeringan Terhadap Mutu Simplisia Sambiloto. Bull.Littro, 17 (1):1-5.

Maycs, P.A. 2003. Biosintesis Asam Lemak. In: Munsy RK, Granner DK, Maycs PA, Rodwell VW. Editors Biokimia: Jakarta.

Mustapha N., Abubakar and Runner, R. T., and Majinda. 2016. GC-MS Analysis and Preliminary Antimicrobial Activity of Albizia adianthifolia (Schumach) and Pterocarpus angolensis (DC). Medicines, 3(3). doi:10.3390/medicines3010003.

Novitasari, M.R., Febrina, L., Agustina, R., Agung, R., Rolan, R. 2016. Analisis GC-MS Senyawa Aktif Antioksidan Fraksi Etil Asetat Daun
Libo (Ficus variegata Blume.). Jurnal Sains dan Kesehatan, 1(5) : 2303-0267.

Pramana, D. 2013. Isolasi Zat warna (Antosianin) alami dari buah Senduduk (Melastoma malabathricum L.) dengan metode ekstraksi padat cair (Leaching).[Tugas Akhir]. Teknik Kimia Polsri. Diterbitkan

Pino, J.A., Regalado, E.L., Rodriguez, J.L., Fernandez, M.D. 2010. Phytochemical analysis and in vitro Free-Radical-Scavenging activities of the essential oils from leaf and fruit of Melaleuca leucadendron L. Chemistry and Biodiversity J, 7(9):2281-8.

Rahyuni, E., Yuniati dan Pitopang, R. 2013. Kajian etnobotani tumbuhan ritual Suku Tajio di Desa K.asimbar, Kabupaten Parigi Moutong. Jurnal of Natural Science 2(2): 4654.

Rajeswari., Rajakumar. dan Ayyasamy. 2015. Evaluation Of Nitrate In Aquatic System: A General View. India. International Journal of Emerging Research in Management \& Technology, 4 (12).

Revanthi, P., Jeyaseelansenthinath, T., and Thirumalakolundhusubramaian, P. 2015. Preliminary Phytochemical Screening and GC-MS analysis of ethanolic extract of Mangrove Plant-Bruguiera Cylindria (Rhizo) L. International Journal of Pharmacognosy and Phytochemical Research, 6: 729-740.

Sell, C.S. 2003. A Fragrant Introduction to Terpenoid Chemistry. The Royal Society of Chemistry: Cambridge. $410 \mathrm{p}$

Suryadarma, I.G.P. 2010. Keanekaragaman tumbuhan bahan kebugaran dalam naskah lontar rukmini tatwa masyarakat Bali. Biota. 15 (2): 294-305.

Ueki,M., Asaga, T., Chujo K., Ono, J., Iwanaga, Y., dan Taie S. 2008. d'Allose protects against endotoxemic acute renal injury. Journal of Bioscience and Bioengineering. https://doi.org/10.1263/jbb.105.481

Van Valkenberg, J.L.C.H. dan Bunyapraphatsara,N. 2001. “Melastoma malabathricum L.," In: van Valkenburg, J.L.C.H. and Bunyapraphatsara, N. (Eds). Plant Resources of South-East Asia No. 12(2): Medicinal and poisonous plants 2. Leiden, The Netherlands: Backhuys Publisher, pp. 365-366.

Zhao, J., Davis, L.C., dan Verpoorte, R. 2005. Elicitor signal transduction leading to production of plant secondary metabolites. Biotechnol Adv, 23 (4):283-333. 